\title{
Effect of the flavonoid baicalin on the proliferative capacity of bovine mammary cells and their ability to regulate oxidative stress
}

\author{
Marie-Hélène Perruchot $^{1}$ ， Florence Gondret ${ }^{1}$, Fabrice Robert ${ }^{2}$, Emilien Dupuis ${ }^{2}$, Hélène Quesnel ${ }^{1}$, \\ Frédéric Dessauge ${ }^{\text {Corresp. } 1}$ \\ 1 PEGASE, INRA, AGROCAMPUS OUEST, Rennes, France \\ 2 CCPA Group, Janzé, France \\ Corresponding Author: Frédéric Dessauge \\ Email address: frederic.dessauge@inra.fr
}

Background. High-yielding dairy cows are prone to oxidative stress due to the high metabolic needs of homeostasis and milk production. Oxidative stress and inflammation are tightly linked; therefore, anti-inflammatory and/or natural antioxidant compounds may help improve mammary cell health. Baicalin, one of the major flavonoids in Scutellaria baicalensis, has natural antioxidant and anti-inflammatory properties in various cell types, but its effects on bovine mammary epithelial cells (BMECs) have not been investigated. Methods. Explants from bovine mammary glands were collected by biopsy at the peak of lactation (approximately 60 days after the start of lactation) ( $n=3$ animals) to isolate BMECs corresponding to mature secretory cells. Cell viability, apoptosis, proliferative capacity and ROS production by BMECs were measured after increasing doses of baicalin were added to the culture media in the absence or presence of $\mathrm{H}_{2} \mathrm{O}_{2}$, which was used as an in vitro model of oxidative stress. Results. Low doses of baicalin ( 1 to $10 \mu \mathrm{g} / \mathrm{mL}$ ) had no or only slightly positive effects on the proliferation and viability of BMECs, whereas higher doses (100 or $200 \mu \mathrm{g} / \mathrm{mL}$ ) markedly decreased BMEC proliferation. Baicalin decreased apoptosis rate at low concentrations $(10 \mu \mathrm{g} / \mathrm{mL})$ but increased apoptosis at higher doses. ROS production was decreased in BMECs treated with increasing doses of baicalin compared with untreated cells, and this decreased production was associated with increased intracellular concentrations of catalase and NRF-2. Irrespective of the dose, baicalin pretreatment attenuated $\mathrm{H}_{2} \mathrm{O}_{2}$-induced ROS production. Discussion. These results indicate that baicalin exerts protective antioxidant effects on bovine mammary cells. This finding suggests that baicalin could be used to prevent oxidative metabolic disorders in dairy cows. 


\section{Effect of the flavonoid baicalin on the proliferative capacity}

\section{2 of bovine mammary cells and their ability to regulate}

\section{3 oxidative stress}

4 Marie-Hélène Perruchot ${ }^{1}$, Florence Gondret ${ }^{1}$, Fabrice Robert ${ }^{2}$, Emilien Dupuis ${ }^{2}$, Hélène

5 Quesnel $^{1}$, Frédéric Dessauge $^{1^{*}}$

6

7 1PEGASE, INRA, AGROCAMPUS OUEST, 35590, SAINT-GILLES, FRANCE

$8 \quad{ }^{2}$ CCPA Group, ZA du bois de Teillay, 35150 Janze, France

9

10

11

* Corresponding author:

Frédéric DESSAUGE

PEGASE, INRA, AGROCAMPUS OUEST, 35590, SAINT-GILLES, FRANCE

15

frederic.dessauge@inra.fr 


\section{Abstract}

Background. High-yielding dairy cows are prone to oxidative stress due to the high metabolic needs of homeostasis and milk production. Oxidative stress and inflammation are tightly linked; therefore, anti-inflammatory and/or natural antioxidant compounds may help improve mammary cell health. Baicalin, one of the major flavonoids in Scutellaria baicalensis, has natural antioxidant and anti-inflammatory properties in various cell types, but its effects on bovine mammary epithelial cells (BMECs) have not been investigated.

Methods. Explants from bovine mammary glands were collected by biopsy at the peak of lactation (approximately 60 days after the start of lactation) ( $\mathrm{n}=3$ animals) to isolate BMECs corresponding to mature secretory cells. Cell viability, apoptosis, proliferative capacity and ROS production by BMECs were measured after increasing doses of baicalin were added to the culture media in the absence or presence of $\mathrm{H}_{2} \mathrm{O}_{2}$, which was used as an in vitro model of oxidative stress.

Results. Low doses of baicalin ( 1 to $10 \mu \mathrm{g} / \mathrm{mL}$ ) had no or only slightly positive effects on the proliferation and viability of BMECs, whereas higher doses (100 or $200 \mu \mathrm{g} / \mathrm{mL}$ ) markedly decreased BMEC proliferation. Baicalin decreased apoptosis rate at low concentrations (10 $\mu \mathrm{g} / \mathrm{mL}$ ) but increased apoptosis at higher doses. ROS production was decreased in BMECs treated with increasing doses of baicalin compared with untreated cells, and this decreased production was associated with increased intracellular concentrations of catalase and NRF-2. Irrespective of the dose, baicalin pretreatment attenuated $\mathrm{H}_{2} \mathrm{O}_{2}$-induced ROS production. 
40 Discussion. These results indicate that baicalin exerts protective antioxidant effects on bovine

41 mammary cells. This finding suggests that baicalin could be used to prevent oxidative metabolic

42 disorders in dairy cows.

\section{Introduction}

The early lactation period in dairy cows is marked by severe metabolic stress due to high energy demand of milk production and due to concomitant limited feed intake, thus resulting in the mobilization of body reserves and a high risk of metabolic (e.g., milk fever and ketosis) and infectious diseases such as mastitis (Sordillo \& Aitken 2009). High demand for energy and nutrients requires large amounts of molecular oxygen for aerobic metabolism, which is accompanied by increased rates of reactive oxygen species (ROS) production (Aitken et al. 2009). This excessive production of ROS during the periparturient period can overwhelm the systemic and organ-specific antioxidant defenses, resulting in development of oxidative stress (Bernabucci et al. 2005; Castillo et al. 2005; Sordillo et al. 2007) and various alterations in metabolic and cell survival mechanisms within the mammary gland (Piantoni et al. 2010). Therefore, oxidative stress has been implicated in many pathophysiological conditions of dairy cows (Allison \& Laven 2000; Harrison et al. 1984; Miller et al. 1993). The proper balance between oxidants and antioxidants is likely essential for maintaining dairy cow health and 57 performance. Various macro- and micronutrients are directly involved in regulating cellular function and health through their anti-inflammatory and/or antioxidant properties (Kim et al. 2004; Mueller et al. 2010). Many bioactive compounds, such as flavonoids, that have antiinflammatory or antioxidant properties have been found in edible medicinal plants. Among these 
62 plants, Scutellaria baicalensis (S. baicalensis) is one of the major medicinal herbs used for the 63 treatment of various inflammatory diseases, hepatitis, tumors and diarrhea in East Asian

64 countries. The flavones baicalin, wogonoside and their respective aglycones, baicalein and

65 wogonin, are the main bioactive compounds in Scutellaria roots. In particular, baicalin is

66 considered the most abundant glycoside that contributes to the quality of S. baicalensis'

67 bioactivity, and the anti-apoptotic, antioxidant, antitumor, anti-inflammatory and immune

68 modulatory activities of baicalin have been observed in different cell types and animal models

69 (Chou et al. 2003; Hsieh et al. 2007; Kim et al. 2004; Liu et al. 2008; Mueller et al. 2010;

70 Shapiro et al. 2009; Xu et al. 2010). In the mammary gland, particularly in mammary epithelial

71 cells, the effects of baicalin have not been well described (Guo et al. 2014). Recently, baicalin

72 has been suggested as a potentially useful therapeutic agent for the treatment of bacterial

73 infections in a mouse model of mastitis. Cell culture systems that utilize extracellular sources of

$74 \mathrm{H}_{2} \mathrm{O}_{2}$ are useful for studying the toxicity and cellular adaptive responses to oxidative stress (Gille

75 \& Joenje 1992). Hence, the purposes of this study were (i) to investigate the effects of baicalin

76 on cell viability, proliferation, and oxidative stress in bovine mammary epithelial cells (BMECs);

77 and (ii) to determine whether baicalin has a protective effect on BMECs by restoring the cell

78 redox state after $\mathrm{H}_{2} \mathrm{O}_{2}$-induced oxidative stress. This is a first step in understanding the possible

79 beneficial effects of $S$. baicalensis extract on increased milk production, which was recently

80 observed during the first 60 days postpartum in dairy cows (Robert et al. 2014). 


\section{Materials \& Methods}

89 All the animal procedures were discussed and approved by the CNREEA No. 07 (Local Ethics

90 Committee in Animal Experiment of Rennes) in compliance with French regulations (Decree

91 No. 2013-118, February 07, 2013).

\section{Mammary tissue sampling}

93

94

95

Lactating Holstein multiparous (third lactation) cows $(n=3)$ raised at the INRA experimental barn (UMR PEGASE, Le Rheu, France) were used for mammary tissue collection. The cows were milked twice daily before mammary tissue collection at the peak of lactation (after $60 \mathrm{DMI}$ ). Biopsies from the left and the right halves of the udder (one sample per quarter) were taken approximately halfway between the base of the teat and the dorsal body wall in a region containing a large amount of secretory tissue, according to a method adapted from Farr et al. (Farr et al. 1996). Mammary biopsies were sliced into small explants $\left(5 \mathrm{~mm}^{3}\right)$ for tissue digestion and cell isolation.

\section{BMEC preparation and primary culture}

Mammary explants were digested and dissociated as described by Perruchot et al. (2016) (Perruchot et al. 2016). To ensure that the isolated BMECs corresponded to mature secretory 
105 cells, the cells were sorted by flow cytometry using fluorescein isothiocyanate (FITC) anti-rat

106 IgG1 CD49f ( $\alpha 6$ integrin) (ref. 13-097-246, Miltenyi Biotec). Isotype controls were used for

107 each antibody to eliminate nonspecific background fluorescence. Flow cytometric analysis was

108 performed on a data set of 30000 events (single cells) using a MACSQuant ${ }^{\circledR}$ Analyzer10

109 (Miltenyi Biotec), and the data were analyzed using MACSQuantify analysis software (Miltenyi

110 Biotec). The results are expressed as percentages (dot plot analysis) (Figure 1A).

The BMECs were cultured in 96 -well plates at a density of 5000 cells/100 $\mu \mathrm{L} /$ well in

112 MGE-P epithelial cells growth medium containing 10\% FBS, 1X penicillin/streptomycin, $0.25 \mathrm{X}$

113 insulin-transferrin-selenium (ITS) without lactogenic hormones according to methods described

114 in Perruchot et al., 2016. All cell culture products were purchased from Sigma-Aldrich (Saint-

115 Quentin Fallavier, France). All BMEC cultures were grown at $37^{\circ} \mathrm{C}$ under $95 \%$ air and $5 \% \mathrm{CO} 2$.

116

117 Cell viability, cell death and proliferation assays

118 Cell viability was determined using 3-(4,5-dimethylthiazol-2-yl)-2,5-diphenyltetrazolium

119 bromide (MTT) colorimetric assay (Sigma-Aldrich ) to assess the metabolic activity of cells.

120 Briefly, confluent monolayers of BMECs were treated with increasing concentrations of baicalin

$121(0,1,10,100$ and $200 \mu \mathrm{g} / \mathrm{mL})$ for 24 hours. The media were removed at the end of the treatment

122 period, and BMEC monolayers were then exposed to $200 \mu \mathrm{L}$ of MTT solution $(0.5 \mathrm{mg} / \mathrm{mL}$ in

123 PBS) for 2 hours. After washing the cells with PBS, the formazan crystals were solubilized with

124 DMSO (200 $\mu \mathrm{L}$ per well; Sigma-Aldrich Chimie) before the plates were measured at $540 \mathrm{~nm}$

125 using a Multiskan Spectrum microplate reader (Thermo Fisher Scientific) equipped with a

126 spectrophotometer. The results are presented as the mean \pm standard error of the mean (SEM) of

127 triplicate assays from three independent experiments. 

visualize apoptotic and necrotic cells. An Alexa Fluor 488 Annexin-V/Dead Cell Apoptosis Kit

130 (Thermo Fisher Scientific) was used according to the manufacturer's recommendations. Briefly,

131 BMECs cultured with or without increasing doses of baicalin (0 to $200 \mu \mathrm{g} / \mathrm{mL}$ ) during 24 hours

132 were incubated for 15 min with annexin-V-FITC $(5 \mu \mathrm{g} / \mathrm{mL})$ and PI $(1 \mu \mathrm{g} / \mathrm{mL})$ and then diluted in $133400 \mu \mathrm{L}$ of annexin-binding buffer. Cells were then analyzed by flow cytometry. The following 134 staining controls were used: unstained cells, cells labeled with annexin-V-FITC alone (without $135 \mathrm{PI}$ ), and cells labeled with PI alone (without annexin-V-FITC). For each sample, $2 \times 10^{4}$ events 136 were analyzed.

To assess proliferative capacity, BMECs were cultured for 24 hours with increasing doses of baicalin (from 0 to $200 \mu \mathrm{g} / \mathrm{mL}$ ), then labeled using $10 \mu \mathrm{M} \mathrm{BrdU}$ per well, and re-incubated overnight following the manufacturer's instructions. The amount of labeling was quantified by measuring the absorbance at $370 \mathrm{~nm}$ using a scanning multiwell spectrophotometer (Mithras LB 940, Berthold Technologies) with a reference wavelength of $492 \mathrm{~nm}$. Increased optical density

142 (OD) values indicate a higher proliferation rate.

\section{Oxidative stress assays}

ROS production in BMECs cultured with different doses of baicalin (1 to $100 \mu \mathrm{g} / \mathrm{mL}$ ) H2 (DCFDA), added to the medium. After 90 min or 24 hours of incubation, respectively, the

147 hydroxyl radicals produced by the cells were estimated by quantifying dichlorofluorescein 148 (DCF) using a multidetection microplate reader (Mithras, LB 940) with excitation and emission 
149 wavelengths at $485 \mathrm{~nm}$ and $535 \mathrm{~nm}$, respectively. Samples incubated with $50 \mathrm{U}$ of PEG-SOD

150 were used as negative controls to assess the specificity of the assay.

151

Hydrogen peroxide was also applied to primary BMECs as an in vitro oxidative stress

152 model (Gille \& Joenje 1992). The cytotoxicity of $\mathrm{H}_{2} \mathrm{O}_{2}$ to BMECs was first established by

153 incubating BMECs with increasing concentrations of $\mathrm{H}_{2} \mathrm{O}_{2}(0$ to $1000 \mu \mathrm{M})$ diluted in cell culture

154 media. Cytotoxicity was estimated after 24 hours of treatment as described above. Because a

155 large decrease in cell viability was observed at the highest doses of $\mathrm{H}_{2} \mathrm{O}_{2}$, the following tests

156 were performed with $\mathrm{H}_{2} \mathrm{O}_{2}$ concentrations below $200 \mu \mathrm{M}$. ROS production was monitored in

157 BMECs exposed to increasing doses of $\mathrm{H}_{2} \mathrm{O}_{2}(0,25,50,100$ and $200 \mu \mathrm{M})$ as described above.

158 Finally, the potential of baicalin treatment to protect BMECs against $\mathrm{H}_{2} \mathrm{O}_{2}$-induced oxidative stress was estimated by pretreating BMECs with increasing concentrations of baicalin (24 hours) and then exposing the cells to $\mathrm{H}_{2} \mathrm{O}_{2}(0,25,50$ or $100 \mu \mathrm{M})$ in culture media for an additional 24 hours. Cell viability and ROS production were examined at the end of this period as described 162 above.

\section{Protein extraction and western blot analysis}

Total proteins were extracted with Radioimmunoprecipitation buffer (Fisher Scientific

Illkirch, France) from BMECs cultured for 24 hours with or without increasing concentrations of baicalin $(0,5,10$ and $100 \mu \mathrm{M} / \mathrm{mL})$. Protein concentrations were determined using a BCA Protein Assay Kit (Fisher Scientific Illkirch, France) according to the manufacturer's instructions. The proteins were separated by SDS-PAGE on 4-12\% SDS-polyacrylamide gels (NuPage 4-12\% BisTris, NP0323BOX, Invitrogen Life Technology, Berlin, Germany), transferred to polyvinylidene difluoride membranes (GE Healthcare Bio-Sciences AB, Uppsala, Sweden) and incubated 
171 overnight with primary antibodies against catalase (SC-50508, Santa Cruz) or nuclear factor

172 (erythroid-derived 2)-like 2 (NFE2L2/NFR-2; SC-722, Santa Cruz). Beta-actin (A5441, Sigma)

173 was used as a control. Horseradish peroxidase (HRP)-conjugated secondary antibody was used at

174 1:2500, and chemiluminescence was visualized using an ECL Kit and an ImageQuant LAS4000

175 Biomolecular Imager digital imaging system (GE Healthcare, Velizy-Villacoublay, France).

\section{Statistical analysis}

The data were first tested for normality. Experiments were repeated three times. Data

178 were analyzed by one-way analysis of variance (ANOVA) using the following model: $\mathrm{y}_{\mathrm{ij}}=\mu+$

179 time $_{\mathrm{i}}+\varepsilon_{\mathrm{ij}}(\mathrm{y}=$ viability, proliferation, ROS production, western blot data; $\mu=$ mean; $\mathrm{i}=$ baicalin

180 dose and $\varepsilon=$ =residuals). Tukey's post hoc pairwise analysis was used. Differences were considered

181 significant at $p<0.05$. All statistical analyses were performed using $\mathrm{R}$ software. 


\section{Results}

Effects of baicalin exposure on the viability and apoptotic and proliferative capacities of

\section{BMECs in primary culture}

To study the effects of baicalin on BMECs, we chose to use primary BMECs isolated and isolated adherent BMECs. Prior to use, we verified that the BMECs expressed the classical epithelial cell marker CD49f. Indeed, it is obvious from Figure 1A that the primary BMECs used for this study were epithelial since $91 \%$ expressed CD49f. evaluating the number of viable cells. Viability was significantly enhanced with $10 \mu \mathrm{g} / \mathrm{mL}$ baicalin but was similar under control conditions and medium supplemented with $1 \mu \mathrm{g} / \mathrm{mL}$ 
210 baicalin. Higher doses of baicalin $(100$ and $200 \mu \mathrm{g} / \mathrm{mL})$ dramatically lowered cell viability

211 (Table 1). Specifically, cell viability was two-fold lower after exposure to $200 \mu \mathrm{g} / \mathrm{mL}$ baicalin

212 for 24 hours than under control conditions $(P<0.001)$. Apoptosis was indirectly evaluated

213 through the expression of annexin- $\mathrm{V}$ in cultured BMECs. The proportion of apoptotic cells was

214 lower $(5 \%$ vs. $8 \% ; P<0.05)$ with $10 \mu \mathrm{g} / \mathrm{mL}$ baicalin but was similar under control conditions and

215 medium supplemented with $1 \mu \mathrm{g} / \mathrm{mL}$ baicalin. Higher doses of baicalin resulted in a dose-

216 dependent increase in the proportion of apoptotic cells (Table 1), with 1.6-fold more apoptotic

217 cells with $200 \mu \mathrm{g} / \mathrm{mL}$ baicalin compared with control conditions. The effects of increasing doses

218 of baicalin were also characterized in terms of BMEC proliferation after 24 hours of culture

219 (Figure 1B). Although the lowest concentration of baicalin $(1 \mu \mathrm{g} / \mathrm{mL})$ slightly increased BMEC

220 proliferation $(+10 \%, P<0.05)$ when compared with the control, large doses of baicalin $(100$

$221 \mu \mathrm{g} / \mathrm{mL}$ and $200 \mu \mathrm{g} / \mathrm{mL})$ in medium decreased cell proliferation $(P<0.05)$, with more than $50 \%$

222 fewer proliferative cells at the highest dose of baicalin $(200 \mu \mathrm{g} / \mathrm{mL})$ compared with the control.

223 Phenotypic differences between BMECs cultured in the absence of baicalin (control) or with a

224 high dose of baicalin $(100 \mu \mathrm{g} / \mathrm{mL})$ are shown in Figure 1C, with lower cell density and more

225 disrupted BMEC colonies in the cells treated with $100 \mu \mathrm{g} / \mathrm{mL}$ baicalin. Taken together, these

226 results show that low concentrations $(1$ and $10 \mu \mathrm{g} / \mathrm{mL})$ of baicalin have no or slightly positive

227 effects on BMEC viability, apoptosis and proliferation, whereas large doses (100 and 200

$228 \mu \mathrm{g} / \mathrm{mL}$ ) of baicalin clearly lowered proliferation, impaired viability and increased apoptosis of

229 BMECs.

\section{Baicalin lowered ROS production in confluent BMECs}

Acute exposure (90 min) of baicalin to confluent BMECs, independent of dose, was 
233 media (-80\%, $P<0.001$, Figure 2A). Chronic exposure (24 hours) to baicalin was similarly

234 associated with reduced ROS production by BMECs (Figure 2B) when compared to BMECs

235 cultured in a medium without baicalin. However, the inhibitory effect of baicalin on ROS

236 production was lower at high concentrations (100 and $200 \mu \mathrm{g} / \mathrm{mL}$ ) than at low doses (1 to 50

$237 \mu \mathrm{g} / \mathrm{mL})$.

238

239

240

241

242

243

244

245

246

247

248

249

250

251

252

253

254

To investigate the mechanisms that might be involved in the reduction of ROS production by BMECs when exposed to baicalin, we analyzed the intracellular amounts of catalase, a powerful antioxidant enzyme, and of Nrf-2, a transcription factor that controls the expression of antioxidant genes. A subset of baicalin doses $(5,10$ and $100 \mu \mathrm{g} / \mathrm{mL})$ was tested on BMECs cultured for 24 hours and compared to the control. Treatment of BMECs with baicalin caused a marked increase in catalase and Nrf-2 protein (Figure 3A and 3B). The greatest effect was observed at $10 \mu \mathrm{g} / \mathrm{mL}$ baicalin, with a 3 -fold increase in catalase and Nrf-2 in treated cells compared with control cells. Taken together, low doses of baicalin may improve oxidative stress in BMECs by lowering ROS production and activating antioxidant intracellular defenses.

\section{Baicalin pretreatment limits $\mathrm{H}_{2} \mathrm{O}_{2}$-induced ROS production in BMECs}

To study the possible benefits of baicalin pretreatment of BMECs during oxidative stress, we used an in vitro model of $\mathrm{H}_{2} \mathrm{O}_{2}$-induced oxidative stress. We first evaluated the effect of $\mathrm{H}_{2} \mathrm{O}_{2}$ on BMEC viability to determine the optimal working concentration. The data presented in Figure 4A show that BMEC viability was significantly affected after treatment with $200 \mu \mathrm{M}$ $\mathrm{H}_{2} \mathrm{O}_{2}$. Next, we investigated ROS production by BMECs when increasing doses of $\mathrm{H}_{2} \mathrm{O}_{2}$ were added to the cell medium. An exponential relationship between ROS production and increasing doses of $\mathrm{H}_{2} \mathrm{O}_{2}$ was observed (Figure 4B), with high doses of $\mathrm{H}_{2} \mathrm{O}_{2}(200 \mu \mathrm{M})$ resulting in a 6-fold 
255 increase in ROS production compared to $0 \mu \mathrm{M} \mathrm{H}_{2} \mathrm{O}_{2}$. Finally, increasing doses of $\mathrm{H}_{2} \mathrm{O}_{2}$ were 256 added to BMECs pretreated for 24 hours with increasing doses of baicalin. Although baicalin

257 was not able to inhibit $\mathrm{H}_{2} \mathrm{O}_{2}$-induced ROS production in BMECs, ROS production was

258 significantly lower in pretreated BMECs than in untreated cells (Figure 4C). The largest

259 reduction was observed after treatment with the highest doses of baicalin $(100$ and $200 \mu \mathrm{g} / \mathrm{mL})$,

260 independent of $\mathrm{H}_{2} \mathrm{O}_{2}$ dose. Finally, improved viability after the $\mathrm{H}_{2} \mathrm{O}_{2}$ was observed in cells

261 pretreated with baicalin (Figure 4D) compared to untreated cells, with the highest improvement

262 observed at $5 \mu \mathrm{g} / \mathrm{mL}$ baicalin pretreatment. Altogether, pretreatment of BMECs with baicalin

263 reduced ROS production under normal and oxidative stress conditions and improved cell

264 viability when exposed to an acute stressor.

267 Discussion

The effects of baicalin have been largely studied in vitro in transformed cell types, demonstrating various antitumor, hepatoprotective, anti-inflammatory and antibacterial properties (Chen et al. 2012; Lin et al. 2014b; Wang et al. 2008; Yin et al. 2011; Yu et al. 2015;

271 Zheng et al. 2012). In mammary gland, studies have been dedicated to investigating the role of

272 baicalin as a possible agent for the treatment of breast cancers, showing either no impact on cell

273 viability (Zhou et al. 2017) or a concentration-dependent (50 to $200 \mu \mathrm{M}$ ) decrease in cell

274 viability (Zhou et al. 2009) without affecting programmed cell death in human breast cancer

275 MCF-7 and MDA-MB-231 cells (Zhou et al. 2009). However, the potential beneficial effects of 
276 baicalin on nontumorigenic mammary cells remain unclear. Anti-apoptotic properties of baicalin

277 have been described in a Staphylococcus aureus-induced mouse model of mastitis (Guo et al.

278 2014). In the present study, $1 \mu \mathrm{g} / \mathrm{mL}$ baicalin slightly increased proliferation $(+16 \%)$ and 10

$279 \mathrm{mg} / \mathrm{mL}$ baicalin increased cell viability $(+6 \%)$ and decreased apoptosis $(-35 \%)$ in BMECs

280 cultured for 24 hours. Similarly, Zheng et al. (2014) suggested that the addition of 1 to $10 \mu \mathrm{g} / \mathrm{mL}$

281 baicalin in culture media may have anti-apoptotic effects by increasing anti-apoptotic Bcl-2

282 protein expression and decreasing caspase-3 protein expression in PC12 cells (Zheng et al.

283 2014). Lin et al. (2014) also showed that baicalin pretreatment inhibited mitochondria-mediated

284 apoptosis in vivo at a dose of 1 to $100 \mathrm{mg} / \mathrm{kg}$ baicalin (Lin et al. 2014a). In contrast, in MCF-7 or

285 RAW 264.7 cell lines, low concentrations of baicalin decreased cell survival ( $50 \mu \mathrm{mol} / \mathrm{L}$, or 22

$286 \mu \mathrm{g} / \mathrm{mL}$ ) (Lee et al. 2015; Wang et al. 2008). This finding contrasted with the results of our study,

287 in which high concentrations of baicalin $(100$ or $200 \mu \mathrm{g} / \mathrm{mL})$ had deleterious effects on BMEC

288 viability. Indeed, 24 hours of incubation with the highest dose of baicalin $(200 \mu \mathrm{g} / \mathrm{mL})$ induced

289 massive cell death $(+60 \%)$ and decreased BMEC proliferation $(-50 \%)$ compared with untreated

290 cells. Other studies have reported similar contradictory effects of baicalin on cell features

291 depending on the dose. For instance, a dose-dependent dual effect of baicalin on angiogenesis

292 has been observed in chick embryos (Zhu et al. 2016), with increased cell proliferation in

293 developing blood vessels at a low dose $(10 \mu \mathrm{g} / \mathrm{mL})$ but increased cell death at higher doses $(5$

$294 \mathrm{mg} / \mathrm{mL})$.

Because the development of oxidative stress in dairy cows during the transition period

generally results in various alterations in metabolic and cell survival mechanisms in the

297

mammary gland (Piantoni et al. 2010), we next focused on the potential effects of baicalin on

BMEC ROS production under either normal or challenged conditions. We observed that, 
299 irrespective of the baicalin dose, short (90 min) - and long (24 hours)-term exposure of BMECs

300 to baicalin rapidly decreased ROS production under normal culture conditions. Under normal

301 conditions, cells are protected by a wide range of antioxidant mechanisms, which include

302 intracellular enzymes such as superoxide dismutase (SOD) and catalase, to remove ROS

303 (Schogor et al. 2013). This process is mediated by activation of the nuclear factor-erythroid-2-

304 related factor $2(\mathrm{Nrf} 2)$ a master regulator of the ROS response; its activation regulates the

305 expression of genes that encode cellular defense enzymes and antioxidant proteins that contain

306 an antioxidant response element (Cardozo et al. 2013). Ma et al. (2018) demonstrated that in

307 isolated BMECs exposed to super-physiological doses of $\mathrm{H}_{2} \mathrm{O}_{2}(600 \mu \mathrm{M})$ for 6 hours, the

308 NFE2L2-ARE (NRF2-antioxidant response element) signaling pathway is a vital regulator of

309 oxidative damage and inflammation (Ma et al. 2018). In our study, we showed that intracellular

310 concentrations in catalase and Nrf2 were increased after baicalin treatment. In murine

311 neuroblastomas, baicalin improved SOD activity and promoted the translocation of Nrf2 to the

312 nucleus (Kensler et al. 2007). Moreover, in a rat model of Alzheimer's disease, baicalin

313 treatment increased the activity and gene expression levels of antioxidant enzymes (SOD,

314 catalase, and glutathione peroxidase), and this increase was also associated with Nrf2 activation

315 (Ding et al. 2015). Hence, the current study suggests that baicalin could prevent oxidative stress

316 by decreasing ROS production through the Nrf2 pathway. However, direct evidence should be

317 further provided by using transactivation assays.

In the present study, $\mathrm{H}_{2} \mathrm{O}_{2}$ was used as an in vitro model of oxidative stress (Gulden et al.

319 2010). $\mathrm{H}_{2} \mathrm{O}_{2}$ is a particularly important contributor to pathological events that, compared to

320 superoxide anions, can cause intracellular and extracellular damage depending on the availability

321 of reactive substrates (Multhaup et al. 1997; Yin et al. 2011). In the present study on BMECs, 
322 increasing doses of $\mathrm{H}_{2} \mathrm{O}_{2}$ stimulated ROS production that increased in an exponential manner. In

323 proliferating mammalian cells, the following patterns of $\mathrm{H}_{2} \mathrm{O}_{2}$ responses have been described

324 (Babich et al. 1996; Davies 1999; Wiese et al. 1995): very low doses (3 to $15 \mu \mathrm{M})$ stimulated

325 cellular growth, higher doses $(120$ to $150 \mu \mathrm{M})$ induced a temporary growth arrest, intermediate

326 concentrations (250 to $400 \mu \mathrm{M})$ caused a permanent growth arrest, and high concentrations $(\geq 1$

$327 \mathrm{mM}$ ) induced necrotic cell death. In cancer models such as human breast adenocarcinoma cells

328 (MCF-7), $\mathrm{H}_{2} \mathrm{O}_{2}$ also promoted damage such as DNA fragmentation and cell death (Dasari et al.

329 2006). Hence, cell culture systems that utilize extracellular $\mathrm{H}_{2} \mathrm{O}_{2}$ are especially useful to study

330 the toxicity and cellular responses to oxidative stress. Importantly, the present findings suggest

331 that pretreatment by baicalin protected BMECs from the oxidative stress induced by $\mathrm{H}_{2} \mathrm{O}_{2}$.

332 Indeed, baicalin pretreatment decreased $\mathrm{H}_{2} \mathrm{O}_{2}$-induced ROS production by $50 \%$ and increased

333 cell viability by $10 \%$. Similar to our results in BMECs, pretreatment of MAC-T cells with

334 resveratrol, a natural polyphenolic compound found in many plant species, limited the decrease

335 in cell viability and prevented intracellular ROS accumulation observed after $\mathrm{H}_{2} \mathrm{O}_{2}$ exposure (Jin

336 et al. 2016). Altogether, the results suggest that the antioxidant properties of baicalin may help

337 protect the mammary epithelium under normal or challenged conditions.

339 Conclusions

340 In this study, we demonstrated that baicalin has positive effects on BMECs in vitro by regulating

341 cell proliferation, apoptosis, cell viability and the antioxidant response and that these effects

342 were generally observed at low concentrations of baicalin (1 to $10 \mu \mathrm{g} / \mathrm{mM})$. Recently, dietary

343 supplementation of dairy cows with S. baicalensis extract resulted in increased milk production 
344 during the first 60 days postpartum (Robert et al. 2014). In vivo plasma concentrations of

345 baicalin, which was originally administered as a food additive, were approximately $10 \mu \mathrm{g} / \mathrm{mL}$.

346 Taken together, we suggest the use of baicalin as a natural approach to promote daily cow

347 lactation and health to minimize the negative effects of oxidative stress on dairy cow mammary

348 glands during the peripartum period.

350 Acknowledgements

351 The authors are grateful to the staff of the UMR PEGASE (INRA, Agrocampus Ouest, Saint

352 Gilles, France), especially to Laurence Finot and Frédérique Mayeur for the laboratory analysis.

353 The authors are grateful to American Journal Expert (Durham, NC, USA) for the language

354 editing (certificate verification key: 8E82-2261-FB6B-4509-CCAB).

355

356

357

358

359

360

References

361

Aitken SL, Karcher EL, Rezamand P, Gandy JC, VandeHaar MJ, Capuco AV, and Sordillo LM.

362 2009. Evaluation of antioxidant and proinflammatory gene expression in bovine 
363

364

365

366

367

368

369

370

371

372

373

374

375

376

377

378

379

380

381

382

383

384

385

mammary tissue during the periparturient period. Journal of Dairy Science 92:589-598.

\section{$10.3168 /$ jds.2008-1551}

Allison RD, and Laven RA. 2000. Effect of vitamin E supplementation on the health and fertility of dairy cows: a review. The Veterinary record 147:703-708.

Babich H, Zuckerbraun HL, Wurzburger BJ, Rubin YL, Borenfreund E, and Blau L. 1996. Benzoyl peroxide cytotoxicity evaluated in vitro with the human keratinocyte cell line, RHEK-1. Toxicology 106:187-196.

Bernabucci U, Ronchi B, Lacetera N, and Nardone A. 2005. Influence of body condition score on relationships between metabolic status and oxidative stress in periparturient dairy cows. Journal of dairy science 88:2017-2026. 10.3168/jds.S0022-0302(05)72878-2

Cardozo LF, Pedruzzi LM, Stenvinkel P, Stockler-Pinto MB, Daleprane JB, Leite M, Jr., and Mafra D. 2013. Nutritional strategies to modulate inflammation and oxidative stress pathways via activation of the master antioxidant switch Nrf2. Biochimie 95:1525-1533. 10.1016/j.biochi.2013.04.012

Castillo C, Hernandez J, Bravo A, Lopez-Alonso M, Pereira V, and Benedito JL. 2005. Oxidative status during late pregnancy and early lactation in dairy cows. Veterinary journal 169:286-292. 10.1016/j.tvj1.2004.02.001

Chen WC, Kuo TH, Tzeng YS, and Tsai YC. 2012. Baicalin induces apoptosis in SW620 human colorectal carcinoma cells in vitro and suppresses tumor growth in vivo. Molecules 17:3844-3857. 10.3390/molecules 17043844

Chou TC, Chang LP, Li CY, Wong CS, and Yang SP. 2003. The antiinflammatory and analgesic effects of baicalin in carrageenan-evoked thermal hyperalgesia. Anesthesia and analgesia 97:1724-1729. 
386

387

388

389

390

391

392

393

394

395

396

397

398

399

400

401

402

403

404

405

406

407

408

Dasari A, Bartholomew JN, Volonte D, and Galbiati F. 2006. Oxidative stress induces premature senescence by stimulating caveolin-1 gene transcription through p38 mitogen-activated protein kinase/Sp1-mediated activation of two GC-rich promoter elements. Cancer research 66:10805-10814. 10.1158/0008-5472.CAN-06-1236

Davies KJ. 1999. The broad spectrum of responses to oxidants in proliferating cells: a new paradigm for oxidative stress. IUBMB life 48:41-47. 10.1080/713803463

Ding H, Wang H, Zhao Y, Sun D, and Zhai X. 2015. Protective Effects of Baicalin on Abeta(1)((4)(2)-Induced Learning and Memory Deficit, Oxidative Stress, and Apoptosis in Rat. Cellular and molecular neurobiology 35:623-632. 10.1007/s10571-015-0156-z

Farr VC, Stelwagen K, Cate LR, Molenaar AJ, McFadden TB, and Davis SR. 1996. An improved method for the routine biopsy of bovine mammary tissue. Journal of dairy science 79:543-549.

Gille JJ, and Joenje H. 1992. Cell culture models for oxidative stress: superoxide and hydrogen peroxide versus normobaric hyperoxia. Mutation research 275:405-414.

Gulden M, Jess A, Kammann J, Maser E, and Seibert H. 2010. Cytotoxic potency of H2O2 in cell cultures: impact of cell concentration and exposure time. Free radical biology \& medicine 49:1298-1305. 10.1016/j.freeradbiomed.2010.07.015

Guo M, Cao Y, Wang T, Song X, Liu Z, Zhou E, Deng X, Zhang N, and Yang Z. 2014. Baicalin inhibits Staphylococcus aureus-induced apoptosis by regulating TLR2 and TLR2-related apoptotic factors in the mouse mammary glands. European journal of pharmacology 723:481-488. 10.1016/j.ejphar.2013.10.032

Harrison JH, Hancock DD, and Conrad HR. 1984. Vitamin E and selenium for reproduction of the dairy cow. Journal of dairy science 67:123-132. 10.3168/jds.S0022-0302(84)81275-8 
409 Hsieh CJ, Hall K, Ha T, Li C, Krishnaswamy G, and Chi DS. 2007. Baicalein inhibits IL-1beta-

410

411

412

413

414

415

416

417

418

419

420

421

422

423

424

425

426

427

428

429

430

and TNF-alpha-induced inflammatory cytokine production from human mast cells via regulation of the NF-kappaB pathway. Clinical and molecular allergy : CMA 5:5. $10.1186 / 1476-7961-5-5$

Jin X, Wang K, Liu H, Hu F, Zhao F, and Liu J. 2016. Protection of Bovine Mammary Epithelial Cells from Hydrogen Peroxide-Induced Oxidative Cell Damage by Resveratrol. Oxidative medicine and cellular longevity 2016:2572175. 10.1155/2016/2572175

Kensler TW, Wakabayashi N, and Biswal S. 2007. Cell survival responses to environmental stresses via the Keap1-Nrf2-ARE pathway. Annual review of pharmacology and toxicology 47:89-116. 10.1146/annurev.pharmtox.46.120604.141046

Kim HP, Son KH, Chang HW, and Kang SS. 2004. Anti-inflammatory plant flavonoids and cellular action mechanisms. Journal of pharmacological sciences 96:229-245.

Lee KJ, Oh YC, Cho WK, and Ma JY. 2015. Antioxidant and Anti-Inflammatory Activity Determination of One Hundred Kinds of Pure Chemical Compounds Using Offline and Online Screening HPLC Assay. Evidence-based complementary and alternative medicine : eCAM 2015:165457. 10.1155/2015/165457

Lin M, Li L, Pokhrel G, Qi G, Rong R, and Zhu T. 2014a. The protective effect of baicalin against renal ischemia-reperfusion injury through inhibition of inflammation and apoptosis. BMC complementary and alternative medicine 14:19. 10.1186/1472-6882-1419

Lin M, Li L, Zhang Y, Zheng L, Xu M, Rong R, and Zhu T. 2014b. Baicalin ameliorates H2O2 induced cytotoxicity in HK-2 cells through the inhibition of ER stress and the activation 
431

432

433

434

435

436

437

438

439

440

441

442

443

444

445

446

447

448

449

450

451

452

of Nrf2 signaling. International journal of molecular sciences 15:12507-12522.

10.3390/ijms 150712507

Liu LL, Gong LK, Wang H, Xiao Y, Wu XF, Zhang YH, Xue X, Qi XM, and Ren J. 2008.

Baicalin inhibits macrophage activation by lipopolysaccharide and protects mice from endotoxin shock. Biochemical pharmacology 75:914-922. 10.1016/j.bcp.2007.10.009

Ma YF, Wu ZH, Gao M, and Loor JJ. 2018. Nuclear factor erythroid 2-related factor 2 antioxidant response element pathways protect bovine mammary epithelial cells against H2O2-induced oxidative damage in vitro. Journal of dairy science 101:5329-5344. $10.3168 /$ jds.2017-14128

Miller JK, Brzezinska-Slebodzinska E, and Madsen FC. 1993. Oxidative stress, antioxidants, and animal function. Journal of dairy science 76:2812-2823. 10.3168/jds.S00220302(93)77620-1

Mueller M, Hobiger S, and Jungbauer A. 2010. Red clover extract: a source for substances that activate peroxisome proliferator-activated receptor alpha and ameliorate the cytokine secretion profile of lipopolysaccharide-stimulated macrophages. Menopause 17:379-387. 10.1097/gme.0b013e3181c94617

Multhaup G, Ruppert T, Schlicksupp A, Hesse L, Beher D, Masters CL, and Beyreuther K. 1997. Reactive oxygen species and Alzheimer's disease. Biochemical pharmacology 54:533539.

Perruchot MH, Arevalo-Turrubiarte M, Dufreneix F, Finot L, Lollivier V, Chanat E, Mayeur F, and Dessauge F. 2016. Mammary Epithelial Cell Hierarchy in the Dairy Cow Throughout Lactation. Stem cells and development 25:1407-1418. 10.1089/scd.2016.0098 
453 Piantoni P, Wang P, Drackley JK, Hurley WL, and Loor JJ. 2010. Expression of metabolic,

454

455

456

457

458

459

460

461

462

463

464

465

466

467

468

469

470

471

472

473

474

tissue remodeling, oxidative stress, and inflammatory pathways in mammary tissue during involution in lactating dairy cows. Bioinformatics and biology insights 4:85-97.

Robert F, Leboeuf L, and Dupuis E. 2014. Scutellaria baïcalensis extract improves milk production in dairy cows. Proceedings of the 65th EAAP meeting Denmark, Copenhagen:372.

Schogor AL, Palin MF, Santos GT, Benchaar C, Lacasse P, and Petit HV. 2013. Mammary gene expression and activity of antioxidant enzymes and oxidative indicators in the blood, milk, mammary tissue and ruminal fluid of dairy cows fed flax meal. The British journal of nutrition 110:1743-1750. 10.1017/S0007114513001220

Shapiro H, Lev S, Cohen J, and Singer P. 2009. Polyphenols in the prevention and treatment of sepsis syndromes: rationale and pre-clinical evidence. Nutrition 25:981-997. 10.1016/j.nut.2009.02.010

Sordillo LM, and Aitken SL. 2009. Impact of oxidative stress on the health and immune function of dairy cattle. Veterinary Immunology and Immunopathology 128:104-109. 10.1016/j.vetimm.2008.10.305

Sordillo LM, O'Boyle N, Gandy JC, Corl CM, and Hamilton E. 2007. Shifts in thioredoxin reductase activity and oxidant status in mononuclear cells obtained from transition dairy cattle. Journal of dairy science 90:1186-1192. 10.3168/jds.S0022-0302(07)71605-3

Wang N, Tang LJ, Zhu GQ, Peng DY, Wang L, Sun FN, and Li QL. 2008. Apoptosis induced by baicalin involving up-regulation of P53 and bax in MCF-7 cells. Journal of Asian natural products research 10:1129-1135. 10.1080/10286020802410664 
475 Wiese AG, Pacifici RE, and Davies KJ. 1995. Transient adaptation of oxidative stress in

476

477

478

479

480

481

482

483

484

485

486

487

488

489

490

491

492

493

494

495

496 mammalian cells. Archives of biochemistry and biophysics 318:231-240.

Xu G, Dou J, Zhang L, Guo Q, and Zhou C. 2010. Inhibitory effects of baicalein on the influenza virus in vivo is determined by baicalin in the serum. Biological \& pharmaceutical bulletin 33:238-243.

Yin F, Liu J, Ji X, Wang Y, Zidichouski J, and Zhang J. 2011. Baicalin prevents the production of hydrogen peroxide and oxidative stress induced by Abeta aggregation in SH-SY5Y cells. Neuroscience letters 492:76-79. 10.1016/j.neulet.2011.01.055

Yu Y, Pei M, and Li L. 2015. Baicalin induces apoptosis in hepatic cancer cells in vitro and suppresses tumor growth in vivo. International journal of clinical and experimental medicine 8:8958-8967.

Zheng J, Hu JD, Chen YY, Chen BY, Huang Y, Zheng ZH, and Liu TB. 2012. Baicalin induces apoptosis in leukemia HL-60/ADR cells via possible down-regulation of the PI3K/Akt signaling pathway. Asian Pacific journal of cancer prevention : APJCP 13:1119-1124.

Zheng WX, Wang F, Cao XL, Pan HY, Liu XY, Hu XM, and Sun YY. 2014. Baicalin protects PC-12 cells from oxidative stress induced by hydrogen peroxide via anti-apoptotic effects. Brain injury 28:227-234. 10.3109/02699052.2013.860469

Zhou QM, Wang S, Zhang H, Lu YY, Wang XF, Motoo Y, and Su SB. 2009. The combination of baicalin and baicalein enhances apoptosis via the ERK/p38 MAPK pathway in human breast cancer cells. Acta pharmacologica Sinica 30:1648-1658. 10.1038/aps.2009.166

Zhou T, Zhang A, Kuang G, Gong X, Jiang R, Lin D, Li J, Li H, Zhang X, and Wan J. 2017. Baicalin inhibits the metastasis of highly aggressive breast cancer cells by reversing 
497 epithelial-to-mesenchymal transition by targeting beta-catenin signaling. Oncology

$498 \quad$ reports $38: 3599-3607.10 .3892 /$ or.2017.6011

499 Zhu D, Wang S, Lawless J, He J, and Zheng Z. 2016. Dose Dependent Dual Effect of Baicalin

$500 \quad$ and Herb Huang Qin Extract on Angiogenesis. PloS one 11:e0167125.

$501 \quad$ 10.1371/journal.pone.0167125

502

503 


\section{Table $\mathbf{1}$ (on next page)}

Effects of baicalin on cell viability and apoptosis in BMEC

BMEC were incubated with different concentrations of baicalin $(0,1,10,100,200 \mu \mathrm{g} / \mathrm{mL})$ for 24 hours in triplicate. Data shown as mean \pm S.E. $* p<0.05$ versus control. 


\section{Table 1.}

2

Baicalin concentration $(\mu \mathrm{g} / \mathrm{mL})$

\begin{tabular}{llllll}
\hline 0 & 1 & 10 & 100 & 200 \\
\hline
\end{tabular}

Viability (OD) $\quad 13330 \pm 998 \quad 13563 \pm 428 \quad 14130 \pm 1113^{*} 7586 \pm 377^{*} 6286 \pm 655^{*}$

Apoptotic cells (\%) $\quad 7.86 \pm 0.5 \quad 7.27 \pm 0.9 \quad 5.11 \pm 0.3^{*} \quad 9.73 \pm 0.3^{*} \quad 12.81 \pm 0.5^{*}$

3

4

5 


\section{Figure 1}

Effects of baicalin on cell proliferation in bovine MEC

A prerequisite to this study was to validate our experimental model, notably by ensuring that isolated MEC corresponded to mature secretory cells. Hence, cells were dispensed at 500,000 and incubated in darkness at $4^{\circ} \mathrm{C}$ for $30 \mathrm{~min}$ with Fluorescein isothiocyanate (FITC) anti-rat IgG1 CD49f ( $\alpha 6$ integrin). CD49f positive cells are gated in red (A). Next, bovine MEC were incubated with different concentrations of baicalin $(0,1,10,100,200 \mu \mathrm{g} / \mathrm{mL})$ for 24 hours in triplicate. (B) Cell proliferation was measured during 16 hours using BrDU cell incorporation. MEC were plated in 96 well-plates at a density of 5000/well. Increased Mean Fluorescence Intensity (MFI) values denoted higher proliferation rates in MFI (x1000). Data shown as mean \pm S.E. $* p<0.05$ versus control (B) Phase contrast images of MEC in culture incubated with $0 \mu \mathrm{g} / \mathrm{mL}$ of baicalin (left panel) and $100 \mu \mathrm{g} / \mathrm{mL}$ of baicalin (right panel). Black bar stands for $50 \mu \mathrm{m}(\mathrm{C})$. 
A

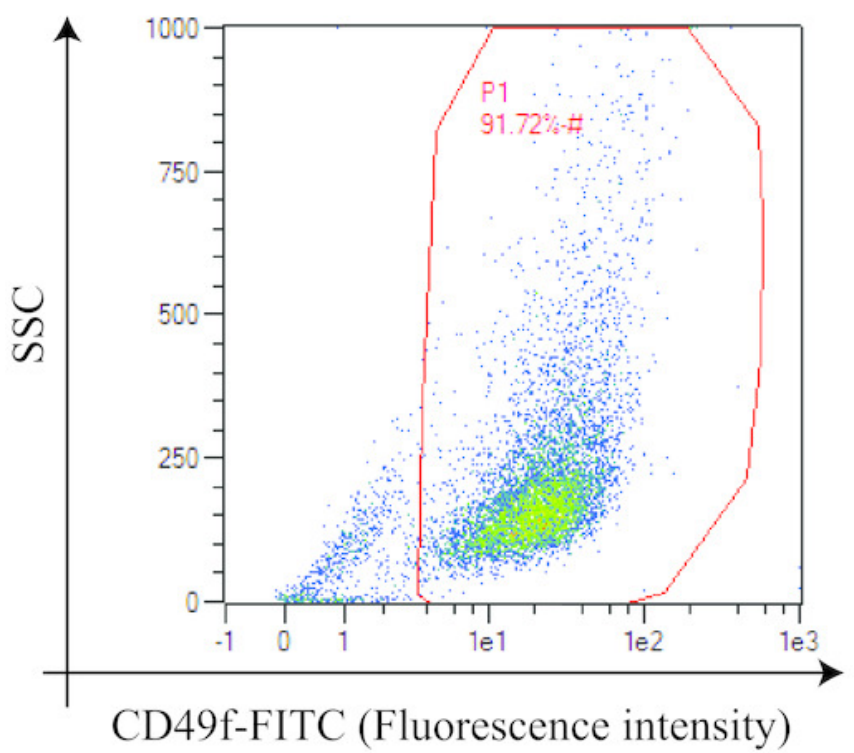

C

Control

$50 \mu \mathrm{m}$
B

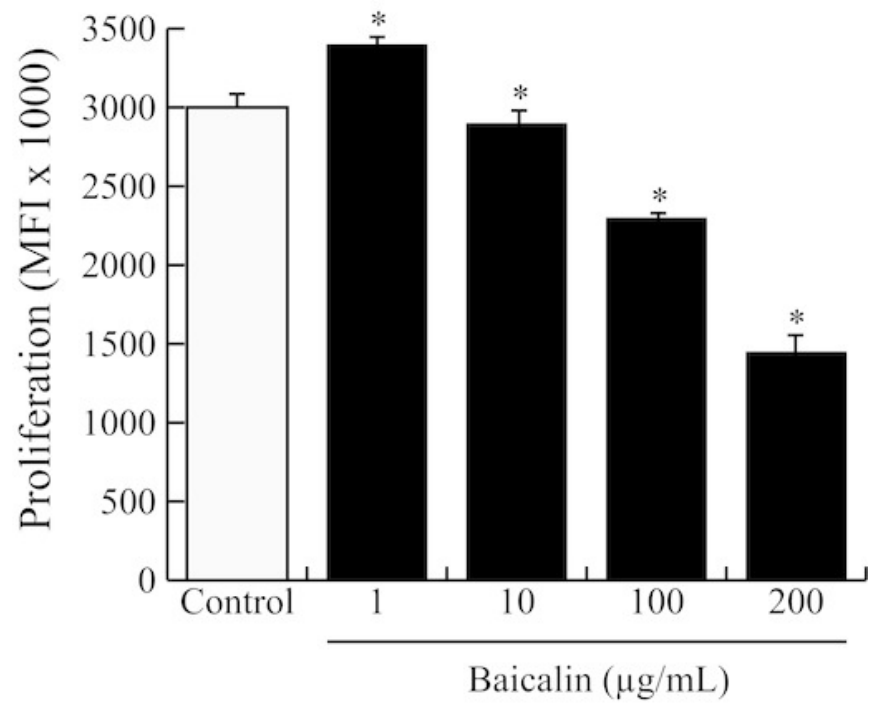

Baicalin $(100 \mu \mathrm{g} / \mathrm{mL})$

Perruchot et al., 2018, Figure 1 


\section{Figure 2}

Effects of baicalin on Nrf-2 and catalase in bovine MEC.

MEC were cultured for 24 hours in medium without (control) or with different concentrations of baicalin (5, 10 and $100 \mu \mathrm{g} / \mathrm{mL})$. The cells were lysed in MPER buffer for total protein extraction, and $15 \mu \mathrm{g}$ of protein was analysed using electrophoresis and Western blotting (Catalase (A) and Nrf 2 (B) antibodies). Each band was quantified using a molecular imager and for each treatment, Catalase ( $\mathrm{A}, 64 \mathrm{kDa})$ and $\mathrm{Nrf} 2(\mathrm{~B}, 61 \mathrm{kDa})$ data were normalized using actin $(40 \mathrm{kDa})$ data. Experiments have been performed 4 times. $* p<0.05$ versus control. 
A

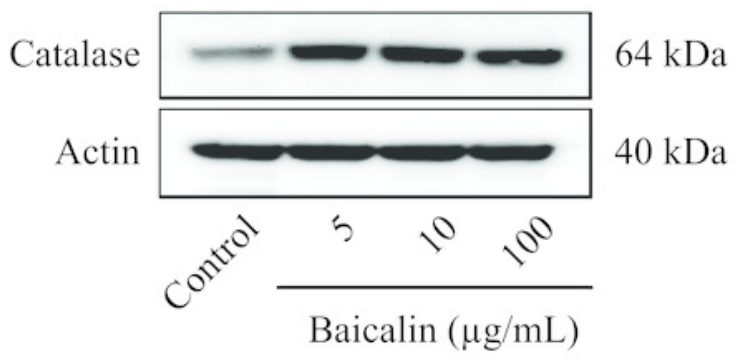

B

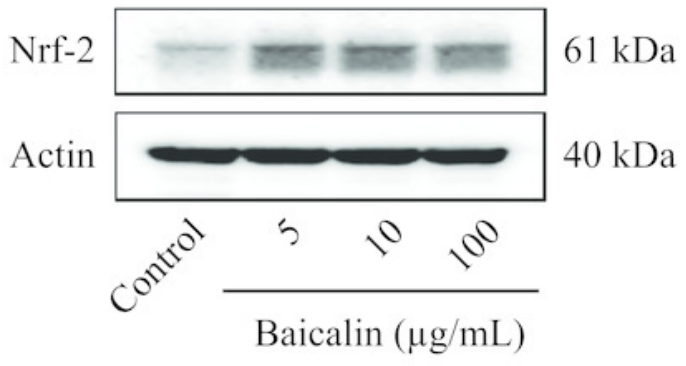

Perruchot et al., 2018, Figure 3

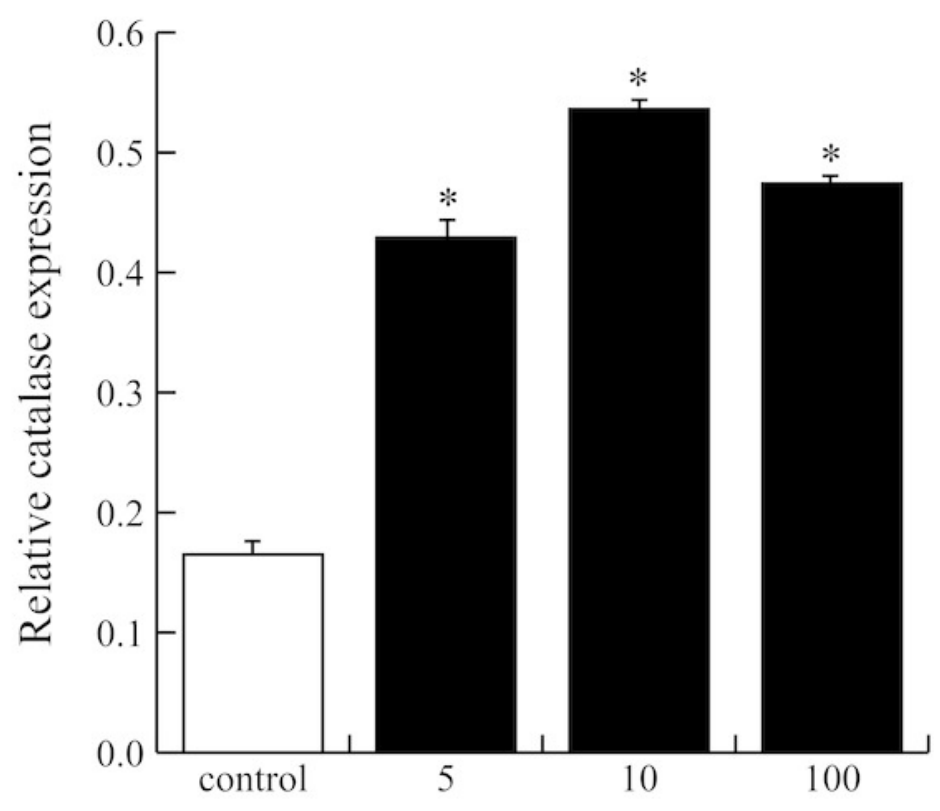

Baicalin $(\mu \mathrm{g} / \mathrm{mL})$

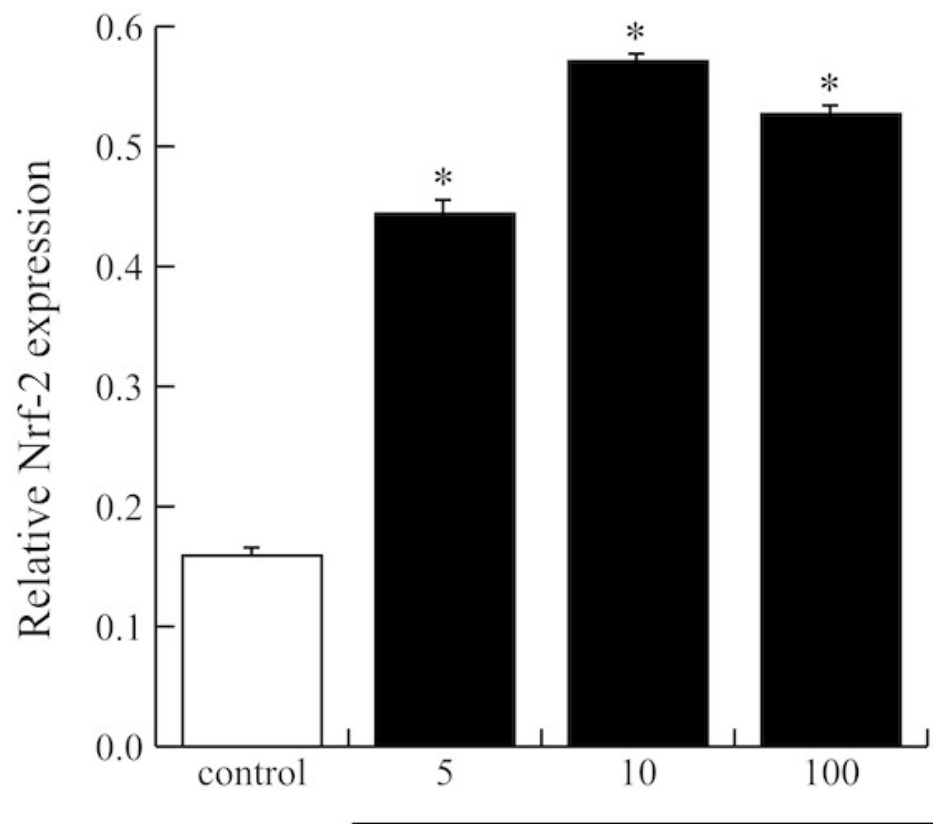

Baicalin $(\mu \mathrm{g} / \mathrm{mL})$ 


\section{Figure 3}

Effects of baicalin on oxidative stress in BMEC after two treatment duration

The effects of baicalin treatment were evaluated under different concentrations ( 0 to 200 $\mu \mathrm{g} / \mathrm{mL}$ ) during $90 \mathrm{~min}(\mathrm{~A})$ and 24 hours (B). The Reactive Oxygen Species (ROS) production was determined by a fluorimetric assay using $5 \mu \mathrm{M}$ of $2^{\prime}, 7^{\prime}$-Dichlorofluorescin diacetate (DCFDA) added to the different media. After incubation, the hydroxyl radicals (ROS) produced by the cells were estimated by quantifying oxidation fluorescent product $2^{\prime}, 7^{\prime}$ Dichlorofluorescein (DCF). The oxidative stress is expressed as light intensity in percentage of the MFI control $\left(0 \mu \mathrm{g} / \mathrm{mL}\right.$ baicalin). ${ }^{*} p<0.05$ versus control. 
A

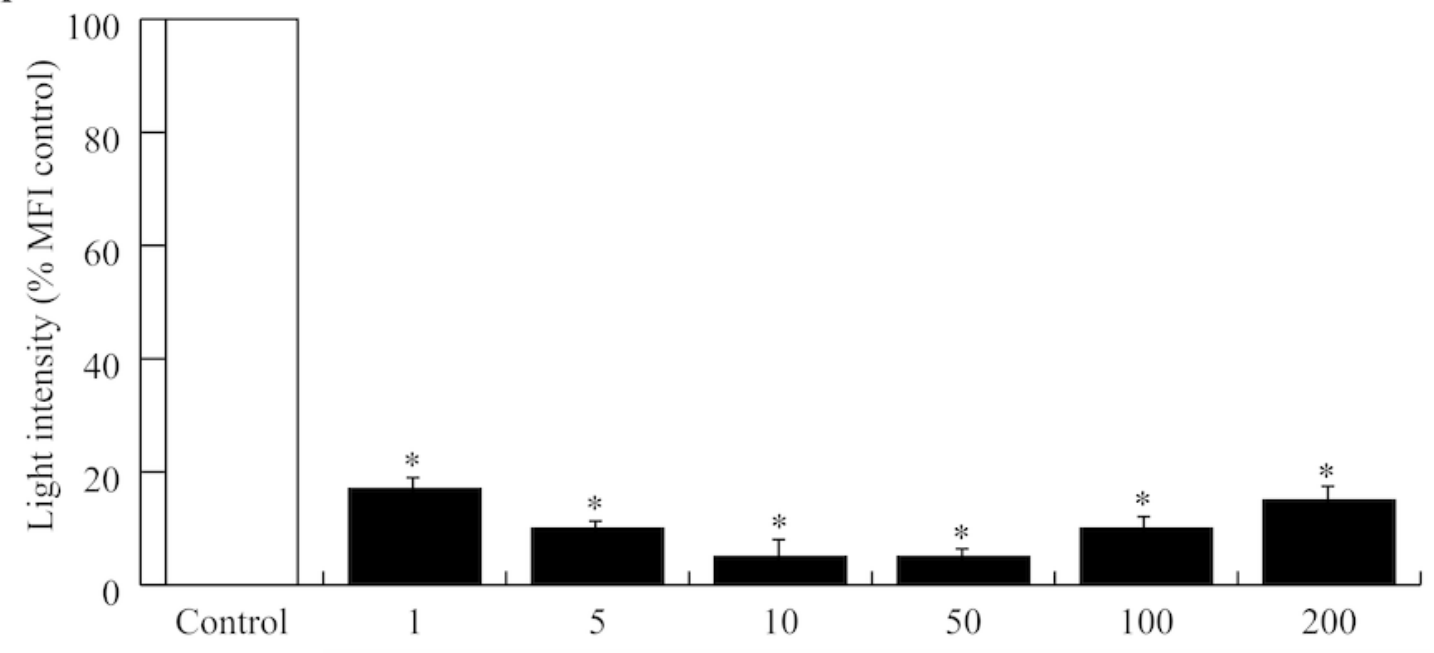

B

Baicalin $(\mu \mathrm{g} / \mathrm{mL})$

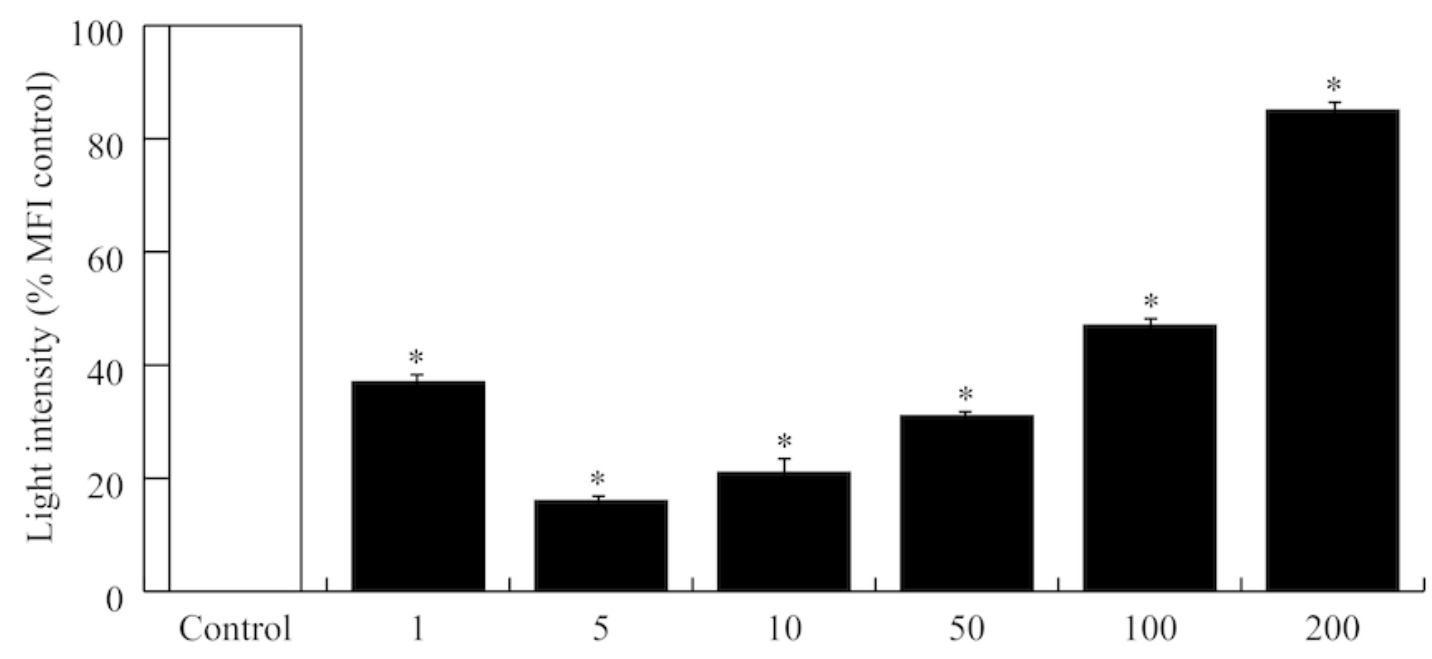

Perruchot et al., 2018, Figure 2

Baicalin $(\mu \mathrm{g} / \mathrm{mL})$ 


\section{Figure 4}

Effects of baicalin pretreatment following $\mathrm{H} 2 \mathrm{O} 2$ stimulation on ROS 3 production in bovine MEC.

BMEC were cultured for 24 hours in medium without (control) or with different concentrations of $\mathrm{H} 2 \mathrm{O} 2$ at increasing doses $(0,25,50,100,200,500,1000 \mu \mathrm{M})$ in triplicate. Data shown as mean \pm S.E. (A) BMEC were plated in 96 well plates at a density of 5000/well. MTT $(25 \mu \mathrm{l}$ of 5 $\mathrm{mg} / \mathrm{mL}$ ) was added to check the cell viability assay (Optical density, OD). * $p<0.05$ versus control (B) The ROS production was determined by a fluorimetric assay. Data are expressed in percentage of the control. $* p<0.05$ versus control (C) and (D) BMEC were pretreated with different concentrations of baicalin (BC, 0 to $200 \mu \mathrm{g} / \mathrm{mL}$ ). 24 hours after, they were exposed to different concentrations of $\mathrm{H} 2 \mathrm{O} 2(0,25,50,100 \mu \mathrm{M})$ in triplicate $(\mathrm{C})$ or to $100 \mu \mathrm{M}$ in triplicate (D). The ROS production (C) was determined by a fluorimetric assay. Data are expressed in arbitrary unit (OD x1000). * $p<0.05$ versus control. Cell viability assay was also assessed (D). Results without Baicalin and with $100 \mu \mathrm{M} \mathrm{H} 2 \mathrm{O} 2$ represent $100 \%$ viability. * $p<0.05$ versus control. 

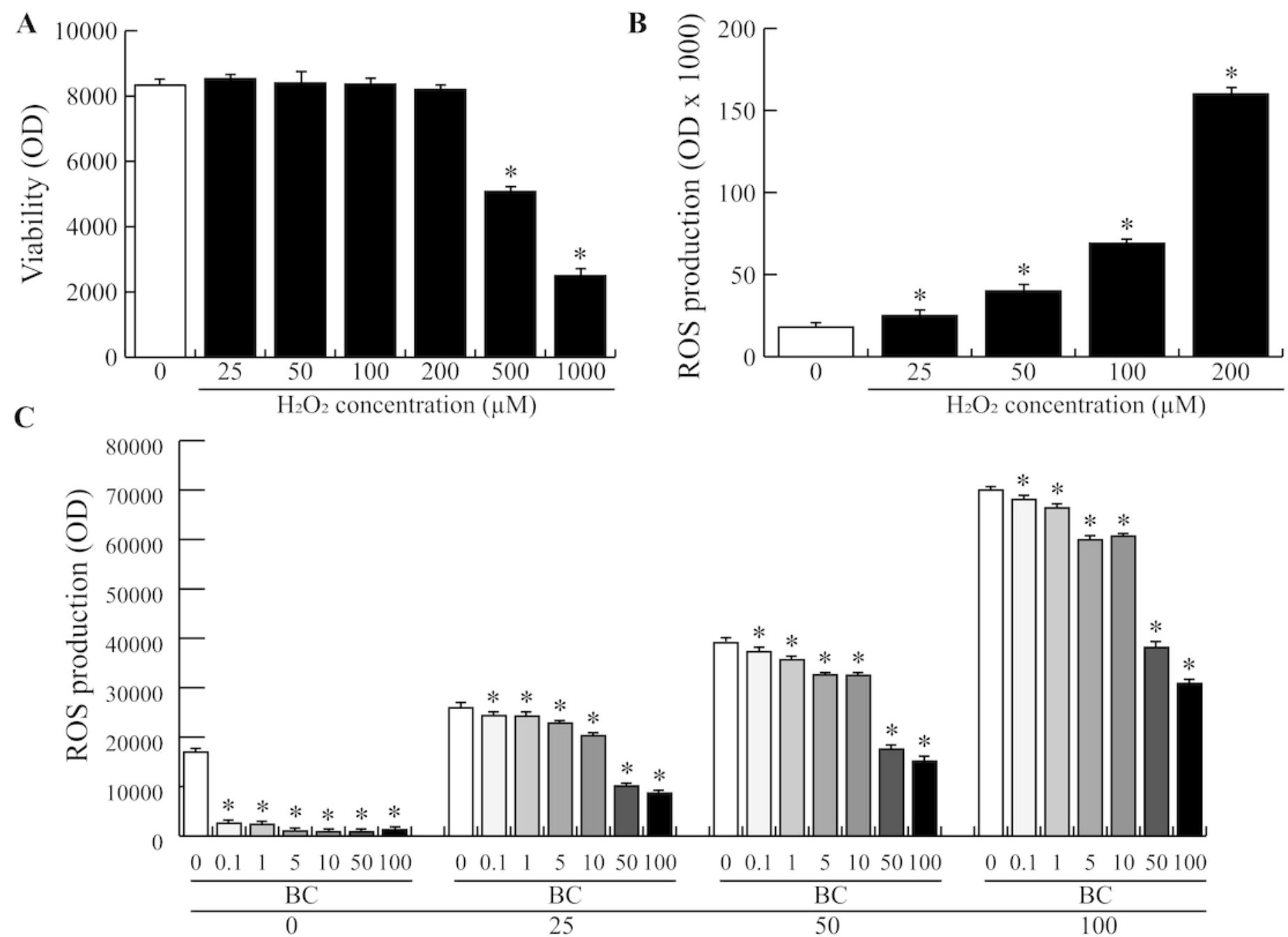

D

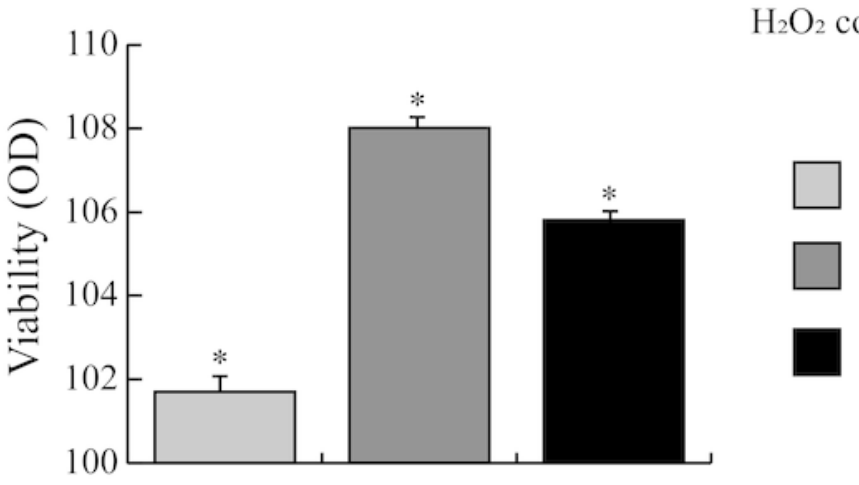

$\mathrm{H}_{2} \mathrm{O}_{2}+1 \mu \mathrm{g} / \mathrm{mL}$ Baicalin

$\mathrm{H}_{2} \mathrm{O}_{2}+5 \mu \mathrm{g} / \mathrm{mL}$ Baicalin

$\mathrm{H}_{2} \mathrm{O}_{2}+100 \mu \mathrm{g} / \mathrm{mL}$ Baicalin

Perruchot et al., 2018, Figure 4 